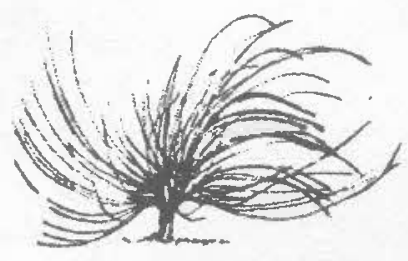

\title{
La desobediencia como forma de resistencia: jóvenes que se hacen sujetos en contextos de "declive" institucional. Al respecto de la enseñanza colegial costarricense
}

\author{
Maurizia D'Antoni ${ }^{\prime}$ \\ Universidad de Costa Rica \\ San José, Costa Rica \\ maurizia.dantoni@gmail.com
}

\author{
Juan Gómez Torres ${ }^{2}$ \\ Universidad Nacional \\ Heredia, Costa Rica \\ ggomezz1@yahoo.es
}

\author{
Luis Gómez Ordóñez ${ }^{3}$ \\ Universidad Nacional \\ Heredia, Costa Rica \\ luishgomezo@gmail.com
}

\author{
José Fabio Soto Arguedas ${ }^{4}$ \\ Universidad Nacional \\ Heredia, Costa Rica \\ chepesoto@gmail.com
}

Recibido: 04 de junio, 2011 - Aprobado: 06 de agosto, 2011

1 Doctora en Comunicación de la Universidad de La Laguna, España. Licenciada en Psicología de la Universidad de Bolonia, Italia. Realizó estudios de especialización en la Universidad de Ginebra, Suiza, en la Facultad de Psicología y ciencias de la Educación. Profesora de la Escuela de Orientación y Educación Especial, Sección de Psicopedagogía de la Universidad de Costa Rica. Profesora e Investigadora de Educología, Centro de Investigación y Docencia en Educación, de la Universidad Nacional.

2 Máster en Estudios Latinoamericanos con énfasis en cultura y desarrollo, Universidad Nacional, Costa Rica. Licenciado en Administración Educativa, Bachiller en Filosofia, en Enseñanza de la Filosofia, en Teología, en Enseñanza de la Religión y en Administración Educativa. Profesor e investigador de Educología, Centro de Investigación y Docencia en Educación (CIDE) de la Universidad Nacional de Costa Rica (UNA).

3 Licenciado en Psicología, egresado de la Maestría en Estudios Latinoamericanos con énfasis en cultura y desarrollo, Universidad Nacional. Profesor e investigador de Educología, Centro de Investigación y Docencia en Educación (CIDE), de la Universidad Nacional de Costa Rica (UNA)

4 Doctor en Mediación Pedagógica, Universidad La Salle, San José Costa Rica, Maestría en Educación, Universidad Estatal de California, Chico, EUA. Licenciado en Pedagogía con énfasis en didáctica, Universidad Nacional, Costa Rica. Bachiller en Informática, Universidad de Costa Rica. Profesor e investigador de Educología, Centro de Investigación y Docencia en Educación (CIDE) de la Universidad Nacional de Costa Rica (UNA). 
Resumen

En el presente ensayo buscamos identificar cuando la desobediencia de los sujetos colegiales se convierte en formas de resistencia. En ese sentido, se acude a la pedagogía crítica para evidenciar estas prácticas de transformación.

Palabras claves: Pedagogía crítica, desobediencia, sometimiento, enajenación, poder, liberación, emancipación y transformación.

\begin{abstract}
In the present paper, we pretend to identify when students' disobedience becomes a way of resistance. In this sense, we make use of the critical pedagogy to support these transformation practices.
\end{abstract}

Keywords: Critical pedagogy, disobedience, submission, alienation, power, liberation, transformation, emancipation.

"No nos convertimos en lo que somos, sino mediante la negación intima y radical de lo que han hecho de nosotros", Jean-Paul Sartre. Prologo a Los condenados de la tierra, de

Franz Fannon.

\title{
A manera de introducción: la pedagogía crítica como praxis reflexiva
}

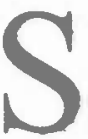

i bien es cierto que desde un punto de vista descriptivo puede pensarse en diversas pedagogias, lo indudable es que si entendemos la pedagogía como una técnica social dedicada al estudio de la educación en tanto proceso de aprendizaje, formación y creación de conocimiento, entonces la pedagogía necesariamente debe ser crítica. Es decir, en sentido restringido, no puede pensarse una verdadera pedagogía sin su dimensión crítica.

Alejarse de esa condición o perder ese horizonte, puede llevar a posturas acríticas, doctrinarias o transmisionistas del estado actual de 
cosas. Eso seria reducir a la educación mediante la pedagogía a la mera reproducción de la cultura, cercenando con ello el carácter crítico trasformador de la educación. Por ende, cuando se hace referencia en este escrito a la pedagogía crítica, se está pensando en ese carácter reflexivo y transformador propio de tal disciplina.

Asi, la pedagogía crítica posee una naturaleza integradora; en lo referente a la teoría y la práctica, supera el artificio dicotómico o fragmentador asignado por la modernidad; parafraseando a Freire, la pedagogía para que sea crítica implica una integración "sine qua non" entre teoría y práctica, pues evoca la convergencia entre conciencia reflexiva, acción ética y política. De este modo conciencia y realidad son inseparables. En este punto, la pedagogía crítica o liberadora (como se le conoce en América Latina), toma prestada del marxismo la categoría de praxis para referir ese sentido integrador de la realidad.

Ese fundamento marxista le permite a la pedagogía crítica pensar la realidad de modo crítico e interrogador, revisando conceptos como: resistencia, emancipación, concientización, problematización, participación y transformación, entre otros. Tales constructos están interrelacionados entre sí, unos llevan inevitablemente a otros o son acciones articuladas en la dinámica de la pedagogía crítica, dicho de otro modo, poseen un estatus dialéctico y dialógico. Por ejemplo, no es posible la emancipación sin acciones de resistencia, de problematización y participación o no sería posible la transformación hacia una sociedad más justa y equitativa sin acciones éticas y políticas congruentes con ese "telos".

Siguiendo a Freire (2001), se puede decir que la pedagogía crítica es un medio alternativo de (auto) liberación de los oprimidos. Es decir, la pedagogía crítica hace un llamado ético y político desde la educación, y por ende desde la pedagogía misma, buscando (des)/(re)educar a los sujetos para que puedan alcanzar una formación integral y no reproduzcan ni legitimen procesos instruccionales y enceguecedores.

\section{La resistencia como acción consciente y liberadora}

La resistencia ayuda a explicar las distintas posiciones políticas de los actores en la escuela, su nivel de conocimiento sobre los problemas y amenazas que les conciemen y su poder real para cambiar el rumbo de las cosas. En ese sentido, teóricos de la Pedagogía crítica como Giroux, sostienen: 
"La resistencia es una valiosa creación teórica e ideológica que ofrece un importante enfoque para analizar la relación entre la escuela y la sociedad amplia. Más aún, provee un nuevo impulso teórico para comprender las formas complejas bajo las cuales los grupos subordinados experimentan su fracaso educativo, y dirige su atención hacia nuevas formas de entender y reestructurar los modos de la pedagogía crítica" (2004: 141).

En esa definición de resistencia entiende a la escuela como un lugar donde quienes resisten se oponen a la subordinación y al sometimiento. Para este autor, en la escuela se fábrica el fracaso escolar, no es resultado del simple abandono ${ }^{5}$ de los educandos por motivos cognitivos, personales o motivacionales, sino más bien, es una construcción ideológica propia de quienes usan la educación y la pedagogía de forma acrítica e intencionada para controlar, normalizar y dominar al otro.

La resistencia como uno de los modos, entre otros, de comportarse ante la dominación, hace referencia a la desobediencia política y ética, aquí los sujetos actúan pluridimensionalmente de modo consciente e intencional contra la dominación. De este modo, la resistencia así entendida puede llevar a la transformación de la realidad por parte de los sujetos que se liberan desde su actuar. Al respecto afirma Giroux: "Finalmente, inherente a la noción radical de resistencia existe una esperanza expresa, un elemento de trascendencia, para la transformación radical" (2004: 145)

Sin embargo, no toda oposición y desobediencia es resistencia. Como se vio, la resistencia como proceso ético y político busca la transformación de las realidades de sumisión y degradación sufridas. La desobediencia como un acto desarticulado, impulsivo, sin intención de cambiar las relaciones opresoras, por el contrario, podría ser en vez de resistencia un acto legitimador de la dominación. Por ello, Giroux recomienda hacer "distinción entre formas de conductas de oposición, que pueden ser usadas para el mejoramiento de la vida humana o para la destrucción o la denigración de los valores humanos básicos." (2004: 146).

Por otra parte, poder y resistencia suelen estar muy relacionados, el poder supone la resistencia. La resistencia está incluida en relaciones de fuerza definidas por el poder, y no existen condiciones de dominación

Deserción escolar, como eufemisticamente se le suele llamar a la exclusión o expulsión. 
que no incluyan formas de resistencia, en una dialéctica entre quienes quieren reducir los espacios de libertad y quienes quieren ensancharlos.

El poder no es monolítico, es ubicuo y móvil y por ende, a la vez, es peligroso por ambiguo; es decir, si el poder supone la resistencia, entonces la resistencia es la contracara sistémica del poder, de allí la importancia de la ruptura emancipatoria más allá del poder y de la resistencia. Por eso, para comprender la resistencia es imperativo desmontar los mecanismos que la hacen operativa. Debido al carácter complejo y móvil del poder es urgente el papel de las Ciencias Sociales como medio para ofrecer herramientas destinadas a la comprensión, interpretación, develación y deconstrucción de los óbices presentes en el poder.

La educación, especialmente a través de la pedagogía, tiene la tarea urgente de analizar la dialéctica entre poder y resistencia presente en todo espacio educativo, para ello puede contar con las herramientas (señaladas) ofrecidas por las Ciencias Sociales en general y la Pedagogía crítica en particular. La tarea no es fácil por el carácter caprichoso de la resistencia como tal, de hecho por la movilidad del poder, más que resistencia hay resistencias concretas y emergentes.

\section{Algunas acciones de resistencia colegial}

Los autores del presente ensayo, han investigado mediante la investigación-acción-participativa en la escuela secundaria pública costarricense. En la investigación se ha recogido evidencia de las situaciones que oprimen al estudiantado y al cuerpo docente, a menudo ambos actores educativos coinciden en el análisis de tales problemáticas.

Entre esos actores hay pocos sujetos con conciencia del problema de sumisión y de la necesidad de transformar las condiciones que la provocan. Tal limitación es común en instituciones educativas cercanas al modelo de educación tradicional, por eso, en este ensayo interesa saber cómo se manifiesta la resistencia en tanto modo alternativo de ser y hacer.

Dicho de otro modo, hay poca conciencia de la debilidad institucional como proyecto educativo emancipador y promotor de calidad de vida, formación integral o vida plena, cuestión nada nueva ni distinta a otros periodos históricos del país. En algunos colegios como uno, con sede en Heredia, (donde se investigó) hay más conciencia de los problemas de sumisión pero sin saber cómo resolverlos. 
Al respecto, para Molina (2007) las acciones de resistencias no pueden reproducir los efectos contra los cuales se está luchando; sin embargo, recordamos que la ética es un compromiso que nace cuando debe nacer. A veces el conocimiento no es suficiente, y en todo caso, la maduración de una perspectiva crítica y emancipatoria es un proceso no resuelto en un solo momento de la vida, tal es el caso de la vida colegial.

La resistencia mostrada por los jóvenes en los colegios costarricenses estudiados (uno en Grecia, otro en la ciudad de Alajuela, otro en San Pedro en San José y el ya referido de Heredia), en general refiere a las prácticas del uso contestatario del cuerpo. El estudiantado resiste frecuentemente contra la constricción enajenante de imposiciones adultocéntricas sobre el cómo habitar el colegio, manifiestas en reglamentaciones internas, circulares ministeriales y en acciones arbitrarias fuera de la ley.

A pesar de lo indicado, no siempre esas conductas divergentes conllevan a la resistencia o son una oposición real ante la dominación. En esos colegios referidos, se evidenció en algunos casos formas del uso del cuerpo utilizadas para resistir y en otros eran utilizadas más bien como procesos de autodefinición identitaria sin una intención explicita de resistir, aunque los adultos solían determinarlos como formas de oposición directa a su autoridad.

También se evidenció que muchas de las manifestaciones juveniles responden aleatoriamente a intereses de mercado, tales como: vestir marcas, usar iconos de grupos musicales, peinarse como el cantante "radical" de moda, sin la menor intención de resistir. Es decir, en la mayoria de los casos señalados se trata de elementos de identidad, todos creados por la misma cultura de masas, para bien o para mal esos elementos a veces cobran el carácter o la apariencia de signo de resistencia.

En las instituciones educativas estudiadas era frecuente observar un control excesivo sobre el cuerpo joven, siendo "clásico" de esa práctica la revisión del largo de las faldas para las mujeres, el largo del pelo en los hombres, la prohibición de adornos en el cuerpo, el uso "correcto del uniforme", entre otras. Para Martín" "no es el pelo el que estudia, somos nosotros, con esa necedad más bien lo indisponen a uno".

El abierto rechazo a tales prácticas y la evidente inutilidad del sometimiento a través del buen uso del uniforme ha abierto la posibilidad

Los nombres señalados en este trabajo son ficticios pues hay un compromiso ético con los participantes de proteger su identidad. 
cada día más generalizada de definir el propio uniforme institucional. Basta con observar el color y tipo de uniforme usado por los y las estudiantes a lo largo y ancho del país. Al respecto, Gerardo, estudiante de décimo año refiere: "yo tengo tantas boletas por uniforme que más bien las colecciono, pero olvídense que me van a cambiar, a mí me gusta vestirme así y más bien he aprendido a vacilarlos" y por su parte Ana de noveno año complementa: "esa basura del uniforme debería quitarla, esta gente es muy necia con esa vara".

Esos actos de resistencia señalados, especialmente en aquellos casos donde se hacen con la intención de oposición y lucha contra la dominación, son hoy en día comunes en estos colegios pero podrian cambiar en un futuro cercano dada la tendencia a la "libertad" de uniforme señalada.

Incluso el uso de uniforme podría desaparecer, como ya sucede en secundarias norteamericanas y europeas. En esos países las aulas parecen un desfile de modas y de identificación con grupos: darks, góticos, emos, punks, vampiros, folks, étnicos, entre otros. En un contexto como ese, las modas ya no representan ninguna resistencia pues han sido absorbidas por el mercado o asumidas como simplemente normales o como identidades de ocasión y de simple autoafirmación de las y los muchachos.

Los estudios realizados en esos colegios han estado a cargo del proyecto denominado "Alfabetización crítica en la cultura escolar" ${ }^{7}$ llevado a cabo del 2005 al 2010. Dicho proyecto da cuenta de más de 90 historias de estudiantes abiertamente declarados en contra del excesivo control sobre sus cuerpos, destacan la existencia de un abuso constante de autoridad. Al respecto, en uno de los colegios, los estudiantes de undécimo año relataron que años atrás se había contratado, por parte de la institución, a un barbero, quien se situaba en la entrada de la institución para cortar el pelo a los varones como condición para ingresar a la misma.

Según lo afirma administrativos de otro colegio (José y Ana), era el mismo director quien les cortaba el cabello a los estudiantes, a quienes llegaban tarde les repartía escobas para barrer las aceras y a aquellos con zapatos sucios les hacía embetunarlos. Todo ello con la

7 La investigación en estos Colegios se ha realizado en distinto momentos. Casi siempre se ha trabajado en dos colegios simultáneamente. 
complacencia y complicidad de profesores, administrativos y padres de familia en general. Del último abuso señalado dan testimonio también los profesores José, Francisco, Elisa y Karla.

Aunque parece haber disminuido la histeria generalizada hacia el largo del pelo en los varones, sin embargo, permanece el nerviosismo con respecto al largo de las faldas de las jóvenes, en ese tema hemos comprobado en las entrevistas que los cuentos sobre manos docentes o administrativas descosiendo el fondo de la falda para alargarla no es una leyenda urbana, corresponde a hechos realmente acontecidos en años recientes.

También continúa la abusiva práctica de despojar al estudiantado de sus adornos corporales, de sus maquillajes y prendas consideradas ajenas al uniforme. Quedando claro la violación a la autodeterminación de las y los muchachos de vestirse como lo deseen, aún y cuando eso pueda generar la paradoja del rechazo y la violencia entre los mismos estudiantes. En ese sentido, María José afirma: "estamos cansadas de tanto control, las cosas no se resuelven con ponernos guardaespaldas (adultos que andan atrás de lo que hace uno), si a uno lo maltratan es peor".

El nerviosismo en las autoridades educativas encargada de controlar el "buen uso" del uniforme, aumenta cuando las estudiantes lo usan de forma sensual o provocativa (según el criterio de dichas autoridades) y muy temidos son los zapatos tipo tenis y las camisetas negras usadas por debajo de la camisa oficial.

Los y las colegiales desafian masivamente y consistentemente el reglamento, poniendo en actos sus prácticas de resistencia ante las imposiciones, las sanciones $\mathrm{y}$, como hemos reportado anteriormente, las constantes acciones institucionales represivas contra el aspecto físico de los y las jóvenes. Uno de los testimonios recogidos acerca de prácticas controladoras del cuerpo adolescente se remonta al 2006, en una institución de las estudiadas, el plantel docente entero, con la orientadora, se ponía en la entrada del colegio, con un metro de costurera para medir el largo de las faldas, así como también controlar otros aspectos del uniforme. Profesores y profesoras esperaban a sus discípulos con boletas en mano.

En cuanto al discurso sobre la obligatoriedad del uso del uniforme, las reacciones son diversas. Parece ser que entre los diferentes actores de la escuela secundaria ha calado la idea del uniforme como 
dispositivo garante de igualdad, como medio para esconder o relativizar las diferencias de clase social, el lugar de procedencia y para evitar desfiles de modas humillantes. A pesar de suponer "necesario" el uniforme, dan poco valor al uniforme tradicional (camisa celeste y pantalón o falda azul), lo consideran desfasado y generador de conflictos para todas las partes.

Los jóvenes que hemos entrevistado del 2006-2010 en los distintos colegios, han dado cuenta de la existencia de una resistencia consciente y abierta contra el uniforme por considerarlo un atuendo "estandarizante". Por eso algunos estudiantes lo usan incumpliendo lo establecido, rompiendo los ruedos de sus pantalones, sin usar faja, con las faldas por fuera, ajustados al cuerpo, sin escudo de la institución, cambiando los tonos de los colores establecidos en el reglamento, sin usar calcetines oficiales, "decorando" sus cuerpos con aretes, brazaletes, collares, prendedores y tatuajes. Lo anterior lo resume las palabras de Keylor, un estudiante de sétimo año, que asegura: "a veces la mala conducta es por decisión de los propios estudiantes que no se sienten escuchados, son rechazados o están cansados de tanto mal trato".

También hay quienes "usan mal" el uniforme de modo intencional pero sin deseos de eliminarlo ni cambiarlo, pues lo consideran importante para la población costarricense con variadas y diversas carencias económicas, para los cuales sería mucho más caro costear los cambios de vestimenta durante los cinco días lectivos de la semana.

Este último argumento también ataca la uniformización, para ellos, usar el uniforme es una forma de mostrarle al mundo el estar dentro de la institución, el ser estudiante de secundaria y el mostrar que no han sido ni esperan ser excluidos de la misma. Los sujetos con tal conciencia presentan un marco de ruptura con el modelo tradicional.

\section{Sobre la desobediencia como forma de resistencia}

Así señalado, hay muchas formas de resistencia, sin duda, una de ellas es la desobediencia, misma que el estudiantado costarricense practica consciente $o$ inconscientemente de forma frecuente, se desobedece lo establecido por los adultos o autoridades. De tal modo, pensar la desobediencia es en primera instancia un ejercicio de pensar el orden, la estructura, las normas y en sentido estricto las relaciones de poder. Ese ordenamiento suele verse como pristina convención de lo objetivo, 
como adalid de la razón y la neutralidad, de la sapiencia y demás formas del saber presuntamente seculares.

Es decir, las relaciones de poder imperantes se "naturalizan", secularizan o culturalizan para legitimar sus beneficios aunque ello contenga en sus entrañas el sometimiento de los otros. Situación paradójica, pues a pesar de ser modernas o "científicas" contienen una verticalidad medieval, escolástica o absolutista en sus jerarquías, como una suerte de resabio del "ancien regime", una capa arqueológica del cieno en las prácticas y discursos sobre la obediencia y la disciplina.

Esas expresiones del poder en la modernidad, teñidas de igualdad, libertad y fraternidad, son a su vez formas de sometimiento objetivadas e invisivilizadas en las normas, pues las reviste el barniz de saberes y relaciones de poder-saber que aún no pasan por la primera desobediencia, la desobediencia de la pregunta. Ese cuestionamiento hace de este ejercicio primero uno de desobediencia epistémica, no porque deba ser un arcano reservado a quienes inquieren la episteme en el claustro de la universidad, sino desde quienes en la irreverencia y el acto mismo de desobedecer la ponen en cuestión, en paréntesis o en duda, no obstante esta se ancle en lo profundo como un dolor visceral.

A pesar de lo anterior, como ya se dijo, la desobediencia no es automáticamente una forma de resistencia, algunas formas de obediencia son positivas o aseguran la calidad de vida, refuerza la dignidad y promueven la criticidad como cuando nos dicen no destruyamos el bosque, no contaminemos los ríos o cuando se nos indica seguir rutas demarcadas en parajes montañosos por nosotros desconocidos, con alta probabilidad de extraviarnos y hasta de perder la vida.

Por tanto, como ya hemos indicado, la resistencia aquí referida es aquella que se revela contra esas formas objetivadas de la razón, del poder-saber, formas impuestas ante la reacción irreverente del cuerpo resistente desde lo volitivo y lo colectivo. Tales objetivizaciones representan un modo de control y vigilancia (normalización, en palabras de Foucault) de los cuerpos, como se ha visto en el caso de los colegiales costarricenses.

El estudiantado evidencia maneras desautorizadas de vestir, planteando escenarios poco comunes, "complicados", de dificil aceptación y catalogados por algunos docentes inmanejables. De allí lo común de plantear la disciplina como salida - aunque paradójicamente ella favorece la insolencia y la violencia-. De este modo, el miedo se impone 
como prescripción ante lo inestable y como única posibilidad ante la imposibilidad de las posibilidades planteadas, se llega a una especie de falacia circular donde se impone la violencia para salir de la violencia.

Así visto, la desobediencia remite a acciones producto de la reflexión y a otras más intuitivas, en ambos casos cuestionando el orden de las cosas y manifestando insatisfacción ante los saberes y acciones deterministas. Ese espíritu interpelante e insatisfecho del ser humano le remite a una condición pedagógica, esto es, preguntar con el fin de aprender. Freire lo refería como pedagogía de la pregunta, una pedagogía opuesta a la pedagogía de las respuestas del saber establecido y absoluto; esa pedagogía de las respuestas, él la denomina: "educación bancaria" (1978), reproductora de relaciones de poder en favor del "status quo" de unos pocos, generando desigualdad, exclusión e injusticia a las mayorías.

Ese acto de asombro y admiración usado desde la antigüedad helénica y posiblemente en otras culturas anteriores, interpela, confronta e interroga sobre lo que aparenta ser y no lo es, sobre lo que parece ser "episteme" pero en el fondo es "doxa" u opinión infundada. Para el docente, ese acto cuestionador suele ser visto o calificado como un acto de irreverente; al menos así lo dejan ver una gran cantidad de colegiales abordados en la investigación referida.

El estudiantado se queja constantemente del verticalismo docente, la confrontación descalificadora y del autoritarismo sapiencial esterilizador del cuestionamiento. El cuestionamiento más reprimido suele ser concretamente el referido a los saberes o al performance del profesor en el aula. En la urdimbre de pasillos no callan, no aceptan el "dictum" de un mundo enmudecido o silenciado para oprimir al otro.

Dicho de otra forma, el saber humano más allá de la discusión epistemológica del realismo y el empirismo, contiene un espíritu socrático o un favoritismo por la palabra, la pregunta o la duda. Cuando el docente acalla ese espíritu suele someter al otro mediante la negación de la palabra, la imposición de su "verdad" y la legitimación y continuación del "status quo" operante. Algunos estudiantes resisten desobedeciendo la inmaculada autoridad negadora de ese derecho constitutivo de la humanidad.

Esta posición lleva a reconocer el papel significativo del lenguaje y de la comunicación como medios para la emancipación (Habermas, 1999), por eso la negación de la palabra a los sujetos (el silencio) y la 
importancia relativa a determinados fragmentos de la historia (de quienes la escriben) conllevan a la "naturalización" del sometimiento.

Negar la palabra o su expresión, mediante la censura de la pregunta equivale a convertir al sujeto (estudiante) en una anónima instancia que, a fuerza de homogenización y prescripciones, pulula respuestas prefabricadas. Esa negación de la pregunta niega a la duda como motor del aprendizaje, no la duda cartesiana olvidada apenas inicia o que es solo excusa para la imposición de la razón, sino la pregunta profunda de las necesidades, espacio vital, intereses y expectativas de los sujetos. Lo anterior, hace referencia a la negación de una lectura crítica de la realidad, sin la cual, según Freire (2001), sería imposible la emancipación de los sujetos educativos.

Esa "naturalización" de la falsa seguridad, del pensamiento único o de la normalidad, es concordante, coherente y contingente a la obediencia de maestros convertidos en censores, de administraciones y gestiones que han pasado a emular en sus peores taras la burocracia autoritaria. Estos docentes no se han liberado de la nefasta herencia del consentimiento sin más - también llamado resignación-, del olvido y de los silencios instituidos, reproduciendo con ello en la práctica esos entornos educativos obedientes, opresores y negadores del mismo sujeto.

\section{Jóvenes que se hacen sujetos en el "declive" de las instituciones}

Duschatzky y Corea (2002) plantean que existe un declive de las instituciones pues están fallando en cuanto a ser constructoras de subjetivación. El tema de la subjetivación sobrepasa las problemáticas ligadas a la función del colegio: ¿será una función pedagógica o bien asistencial? Se trata de una duda a veces expresada por los(as) docentes de las instituciones investigadas, quienes se lamentan de sus estudiantes considerándolos "ineducables" y reprochan la función del colegio convertido en una guardería.

En confirmación con lo anterior, la profesora Ana afirmó: "por dicha van a investigar en esa sección. Con ese grupo es poco lo que se puede hacer" y el profesor Gerardo complementó en otra ocasión: "muchos padres ven al colegio como una guardería y a nosotros como sus niñeras, no les importa si sus hijos pierden el año".

Contrario de lo que estos docentes citados creen, Duschatzky y Corea (2002) proponen que la institución debería transformarse en un 
dispositivo de contención y apoyo a todos los sujetos en ella presentes; de allí que si en la comunidad la función de "guardería" reduce la vulnerabilidad de estudiantes en situación de grave expulsión social, bienvenida sea esa función. Si el colegio logra proteger a los(as) jóvenes de las clases sociales desposeídas de un entorno vulnerabilizante, ha asumido y cumplido su cometido con creces, siempre y cuando logre atraer a las personas jóvenes con programas vinculados a su realidad, su cultura y sus intereses y reconozca su diversidad.

Los cambios económicos y sociales hacen que la escuela secundaria no pueda más constituirse en una promesa de ascenso social (si algún día así fue), para el estudiantado. Sin embargo, esta es sólo parte de las funciones que han cambiado alrededor de la escuela. La "reorganización" de las funciones institucionales ha rasgado el tejido de la subjetivación, no logra -0 no quiere - dar respuesta a las necesidades reales de las personas.

María José estudiante de sétimo año al respecto sostiene: "Los profesores dicen que ellos no pueden hacer mucho por nosotros porque el problema es que muchos venimos mal educados de la casa". En la misma problematización Francini asegura: "Eso que dicen los profesores no es cierto, ellos no conocen como son y viven nuestras familias, ni los problemas ni virtudes que ellas tienen" y Keylor, también de sétimo año, manifiesta: "En nuestro grupo hay muy bajo rendimiento académico pero creo que se debe más a problemas económicos y otros motivos que a nadie le importa resolver". Jonás, estudiante de octavo con cuatro años de estar en el colegio asegura que "el colegio no sirve para nada, que no ha aprendido nada para la vida, que todo lo que enseñan no funciona, nada le dicen de cómo vivir afuera, en esa selva que se come a todos".

Podríamos llamar esas reacciones estudiantiles formas de resistencia, sobre todo si le agregamos el análisis de contingencia aportado por Duschatzky y Corea (2002) a las hipótesis emergentes de nuestras observaciones en colegios costarricenses. Con ello, se puede considerar a la resistencia como un proyecto de liberación, aun sin ser ampliamente planificado o pensado, pues inicia con el descontento consciente sobre su situación en el mundo, deseando cambiarla aunque sea de forma ingenua.

En cuanto a la docencia, en los colegios abordados en la investigación, se observaron prácticas pedagógicas paradójicamente opuestas 
a las citadas en las políticas educativas del $\mathrm{MEP}^{8}$, o bien opuestas a las teorías constructivistas. En los documentos oficiales del MEP se insta a trabajar incluyendo los saberes de los y las estudiantes, a iniciar el proceso de enseñanza desde los intereses, necesidades, expectativas y desde la cultura del estudiantado. A pesar de no hablar de pedagogía crítica refiere aspectos y modelos importantes para generar reflexión y crítica desde el trabajo pedagógico del docente en el aula.

Tales documentos también sugieren reflexionar sobre la función homogenizadora de la institución escolar, con el fin de poner, en el centro a la diversidad de la actividad didáctica, en nuestras aulas. Entre ellos se destaca la política educativa "Hacia el siglo XXI", aún vigente en el país; la misma opta abiertamente por el racionalismo, el humanismo y el constructivismo como fundamentos de nuestra educación, abogando por una educación transformadora.

Pero la distancia entre lo pretendido y lo realizado por el MEP en la práctica suele ser abismal. En los colegios estudiados se presentan planes anuales derivados de la política educativa mencionada y otros documentos más críticos resultantes de congresos pedagógicos y capacitaciones, pretendiendo fomentar la inclusión, la diversidad, la interculturalidad, la participación, los valores solidarios, entre otras buenas intenciones esfumadas en una realidad atiborrada de burocracia, controles e imposiciones.

En esa misma dirección, algunos profesores, presentes en una de las problematizaciones, afirman: "las lecciones tienen muchos contenidos y eso lleva al apego hacia el academicismo, situación que hace que nos olvidemos de aspectos integrales de la formación de los y las estudiantes", así lo expresó Nelson y fue apoyado por la mayoría de los presentes. Además, como agrega Carlos, "hay una sobrepoblación estudiantil que afecta la atención individualizada". Para él "esa sobrepoblación se da en todos los niveles dadas las limitaciones de la infraestructura". Yamileth asegura: "algunos profesores no contextualizan sus lecciones y eso hace poco significativas sus clases para muchos estudiantes".

De allí, que no sea extraña la reacción del estudiantado empeñado en desobedecer y resistir a las acciones hirientes de sus sentimientos e identidad, aplicadas por docentes desencarnados de la realidad estudiantil. Dicha reacción suele ser descalificada con estereotipos

8 Ministerio de Educación Pública de Costa Rica. 
adultocéntricos reduciéndola a un asunto etario, es decir, se considera a las juventudes como "irreflexivas", inconscientes o inmaduras, son adolescencia adolecedora de madurez, prudencia y sensatez. Así, la profesora Sonia afirma: "los estudiantes no tienen la madurez para entender la importancia del estudio, muchos están aquí porque los obligan, pues nosotros somos una guardería para ellos".

No se considera posible ver jóvenes resistiendo contra una especie de "gran mano" institucional que los toca y, simbólicamente mutila su apariencia de gente joven explorando y ensayando sus posibilidades contra la autoridad. Por el contrario, se obvia esa reacción e imponen acciones disciplinarias con la intención de recuperar el control y con ello evitar la posible "ingobernabilidad" provocada por el curso a esa "rebeldía adolescente". Repitiendo un poco lo dicho, se le niega la palabra al sujeto para evitar la desobediencia, la misma no se ve como un proceso pedagógico sino como una amenaza contra la estabilidad institucional.

Si el ámbito pedagógico de esta institución en "declive" ya no puede enseñar (Duschatzky y Corea, 2002), o considera a sus estudiantes "ineducables" (Baquero, Pérez y Toscano, 2008) se corre el riesgo de debilitar las funciones cognitivas, sociales y culturales de los sujetos desobedientes; de allí que la resistencia sea una reacción muy sana en tanto opuesta al aplanamiento y al deterioro de sí.

En las aulas de los colegios estudiados se observó a un estudiantado silenciado y cuando hablaban lo hacían para preguntar por asuntos administrativos como la fecha del examen. La clase solía ser muy seria y aburrida a pesar de los intentos por romper la monotonía realizados por algunos estudiantes quienes, buscando ser graciosos, interrumpen en demasía, utilizan si se puede el celular y los mensajes de texto. En un taller con estudiantes de sétimo año realizado a través de juegos colaborativos, ellos manifestaron asombro, no creía posible jugar en el aula como parte de un proceso de aprendizaje, sostuvieron que al inicio tenían vergüenza pues los juegos son para niños y ellos ya están en el colegio, pero al ver a sus compañeros/as felices se unieron a la fiesta y luego se sintieron cómodos/as.

En el sentido señalado, la fragmentación es omnipresente en la actividad de aula, la seriedad académica presenta a la didáctica de forma segmentada y mecanicista, olvidándose del carácter lúdico de la pedagogía como medio adecuado para enseñar y aprender desde los 
intereses, necesidades y posibilidades de los sujetos educativos. Como ya señalamos, urge aplicar una pedagogía lúdica basada en la pregunta más que en las respuestas.

La profesora Susana afirmó en un taller: "las clases para los estudiantes son poco significativas" y el profesor Abrahán complementó diciendo: "hay dificultades para implementar la evaluación formativa, la evaluación que se implementa es sumativa y rigida, se sigue evaluando como se hacia hace 50 años y los programas impartidos están descontextualizados de la realidad y época vivida por los estudiantes de hoy día y no se responde a sus necesidades ni a sus intereses".

De lo observado en el aula en varios grupos, las interrupciones son la norma, ya sea en el calendario escolar o en la dinámica del aula, los 40 minutos de la clase suelen ser realmente de 20 y hasta menos. De ellos, el docente centraliza la palabra y el estudiantado se caracteriza por ignorarlo, temerle o huirle (se escapa del aula). Al preguntarle a María por qué estaba tan distraía en clases sostuvo: "las clases se parecen todas en la seriedad, son aburridas y ni siquiera nos dejan reír. Cuando uno se ríe le dicen payasos de circo, quien va querer decir algo importante". La misma pregunta se le hizo a un grupo de cinco estudiantes y todos coincidieron diciendo: "hay profesoras que lo ven a uno como el enemigo, siempre pelean con uno y todo lo que hagamos les cae mal".

Pareciera, al menos en las instituciones estudiadas, que se parte de una idea abstracta de estudiante como elemento unificado. Los docentes suelen partir de la idealización de un estudiante de clase media, vallecentrista y aplicado de lleno al estudio. Esa idealización atropella la diversidad y complejidad propia del estudiantado.

A pesar de lo dicho sobre el posible "declive" institucional, no omitimos manifestar la importancia del colegio para los y las estudiantes de secundaria, pues éste sigue siendo un lugar significativo para sus vidas, en él resignifican su cotidianeidad, socializan con sus pares y elaboran nuevos conocimientos (alternativos), todo ello en el en el fluido encuentro con los otros y otras, esto sucede en los pasillos y otros espacios fuera del aula. Pareciera que la guardería como dispositivo sujetivador funciona en el exterior del aula, misma que según el criterio de estudiantes entrevistados es un mal necesario semejante al cumplimiento de una condena en un régimen de libertad condicional. 


\section{A modo de conclusión. La necesidad de evidenciar prácticas de resistencia en los espacios educativos}

Podemos concluir que la desobediencia en tanto forma de resistencia refiere a las tensiones inherentes entre lo diverso y las compulsiones de orden que presiona por la homogenización del espacio y la normalización del otro. Dichas tensiones presuponen prácticas supresoras de la propia subjetividad de las y los educadores y las y los discentes y contienen correlatos con las metáforas de la incompletud del otro, ese otro que en tanto joven se encuentra incompleto a juicio de posiciones de índole adultocéntrica-autoritaria y deben ser llenados mediantes los fragmentos del saber-poder.

Desde un punto de partida comprensivo, interpretativo y de reconocimiento del otro, es posible articular una propuesta que reconozca en la desobediencia, como forma consciente e intencionada de resistencia, la fuerza de las diferencias y la creatividad irreductible a moldes, normas y prescripciones -curas de sueño y ritalina-, y desde allí, partiendo de la especificidad propia de su cultura cada centro de educación debe iniciar un camino de construcción colectiva y de resignificación del espacio escolar.

En las instituciones educativas estudiadas, se suele resistir al autoritarismo y al adultocentrismo, usando para ello la desobediencia como conductas opuestas a la dominación. Se destacaba el uso irreverente del uniforme y la huida del aula como reacciones (in)consientes frente a la opresión, aunque sin llegar a prácticas emancipatorias evidentes.

Así, el problema identificado de mayor importancia es, sobre todo, las diferencias abismales en las relaciones de poder entre docentes y estudiantes, cayéndose en autoritarismos y prácticas de "terrorismo pedagógico" a la hora de elaborar relaciones de conocimiento libre, generando con ello desobediencia que en algunos casos pasa a ser resistencia en busca de la transformación de esas relaciones opresivas. 


\section{REFERENCIAS}

D'Antoni, M., Soto, J., Gómez, L. y Gómez, J. (2006-2010). Proyecto Alfabetización Critica en la cultura escolar: cultura politica y cultura colegial. Heredia, Educología, CIDE, UNA.

Dobles, I., Baltodano, S. y Leandro, V. (2007). Psicologia de la liberación en el contexto de la globalización neoliberal. Acciones, reflexiones y desafios. San José, Costa Rica: Editorial UCR.

Duschatzky, S. y Corea, C. (2002). Chicos en banda. Construcción de la subjetividad en el declive de las instituciones. Buenos Aires, Argentina: Paidós.

Foucault, M. (2000). Vigilar y Castigar: nacimiento de la prisión. $30^{2}$ Edición en Español. DF., México: Siglo XXI.

Foucault, M. (1999). Estrategias de Poder. Volumen II. Barcelona, España: Paidós.

Freire, P. (2001). Pedagogía de la Indagación. Madrid, España: Paidós.

Freire, P. (1978). Pedagogía del oprimido. XXI Edición, Montevideo, Uruguay: S. XXI.

Habermas, Jürgen (1999). Teoria de la acción comunicativa: racionalidad de la acción y racionalización social. Tomo I. México. TAUROS.

Molina, N. (2007). Psicología social de la resistencia. Fundamentos teóricos y ámbitos de impacto. En: Dobles, Baltodano y Leandro, cit. 